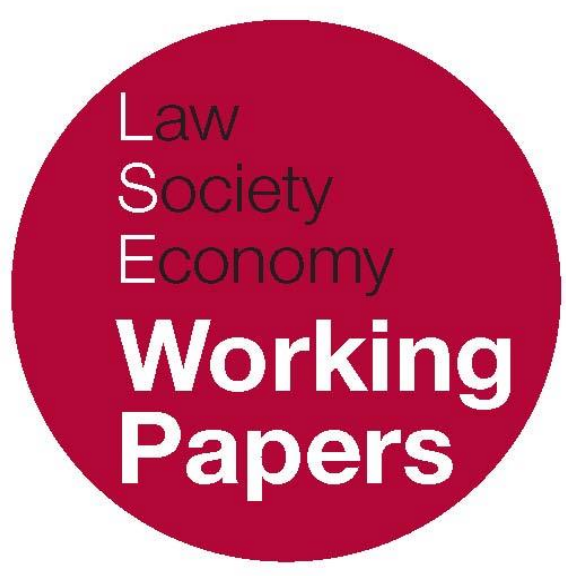

\title{
Digital Regulation: Designing a Supranational Legal Framework for the Platform Economy
}

\author{
Michèle Finck \\ LSE Law, Society and Economy Working Papers 15/2017 \\ London School of Economics and Political Science \\ Law Department
}

\begin{abstract}
This paper can be downloaded without charge from LSE Law, Society and Economy Working Papers at: www.lse.ac.uk/collections/law/wps/wps.htm and the Social Sciences Research Network electronic library at: https://papers.ssrn.com/sol3/papers.cfm?abstract_id=2990043. (C) Michèle Finck. Users may download and/or print one copy to facilitate their private study or for non-commercial research. Users may not engage in further distribution of this material or use it for any profit-making activities or any other form of commercial gain.
\end{abstract}




\title{
Digital Regulation: Designing a Supranational Legal Framework for the Platform Economy
}

\author{
Michèle Finck ${ }^{*}$
}

\begin{abstract}
This paper examines digital data-driven platforms and their impact on contemporary regulatory paradigms. While these phenomena are increasingly proclaimed as paradigm altering in many respects, they remain relatively little understood, including in their regulatory dimension. Lawmakers around the globe including the European Commission are currently trying to make sense of these evolutions and determine how to regulate digital platforms. In its 2016 Communication on Online Platforms, the European Commission proposed various options for regulating the platform economy, including self-regulatory and co-regulatory models. The Commission's assumption that self-regulation or co-regulation can replace topdown legislative intervention in the platform economy forms the background of this paper, which examines these three options to determine their respective suitability. We shall conclude that as command-and-control regulation as well as self-regulation raise significant problems in their application to the platform economy, co-regulation emerges as the most adequate option if certain conditions are met
\end{abstract}

\footnotetext{
* Fellow in Law, London School of Economics and Political Science, and Lecturer in EU Law, Keble College (University of Oxford). I would like to thank Niamh Dunne for very helpful comments and suggestions.
} 
This paper examines digital data-driven platforms and their impact on contemporary regulatory paradigms. The phenomena of digitalization and datafication are disrupting established business models. ${ }^{1}$ Much has been written about the macro- and microeconomic effects of digital platforms and their lifeblood: big data. There appears to be growing consensus that we are currently witnessing a profound paradigmatic change as it has been argued that platforms, in conjunction with big data, artificial intelligence and 3D printing constitute the 'fourth industrial revolution'.2 Yet, despite such proclamations, the digitalization and datafication of the economy remain relatively little understood, including in their regulatory dimension. Lawmakers around the globe including the European Commission are currently trying to make sense of these evolutions and determine how to regulate digital platforms.

In its 2016 Communication on Online Platforms, the European Commission provided a first assessment of the regulatory challenges posed by online platforms and proposed several avenues of how related objectives could be achieved. Strikingly, the Commission not only pondered the possibility for legislative intervention but moreover suggested that 'principles-based self-regulatory/coregulatory measures, including industry tools for ensuring application of legal requirements and appropriate monitoring mechanisms, can play a role'. ${ }^{3}$ This statement, by which the Commission suggests that self-regulation or co-regulation can replace legislative intervention in the platform economy forms the background of this paper, which examines these three options to determine their respective suitability. This question is of no small detail, as in fast-changing environments; regulations have 'enormous potential for both good and harm' and must promote the public good while also preventing adverse effects on innovation. ${ }^{4}$ The EU's first steps in regulating platforms will be of no small importance as they'll shape the contours of the platform economy in the EU, and arguably also beyond. ${ }^{5}$

Regulators are faced with two interrelated questions in this context. Firstly, who should regulate platforms; and, secondly, how they should be regulated. Largely setting aside aspects of substantive law, this essay focuses on the determination of appropriate regulatory actors in this domain. As a preliminary point it should be noted that when discussing platform regulation we need to distinguish their internal operation, including questions of data protection, the legal qualification of nonpersonal data, liability, consumer protection and internal dispute resolution

${ }^{1}$ For an introduction, see Viktor Mayer-Schönberger and Kenneth Cukier, Big Data (Houghton Mifflin Harcourt 2013).

${ }^{2}$ Klaus Schwab, The Fourth Industrial Revolution (World Economic Forum 2016).

3 European Commission, 'Communication on Online Platforms and the Digital Single Market. Opportunities and Challenges for Europe’ COM (2016) 288 final, 5 (hereafter European Commission, 'Communication on Online Platforms and the Digital Single Market').

${ }^{4}$ United States Office of Management and Budget, 'Report to Congress on the costs and benefits of federal regulations,' Chapter 1.3, http://www.whitehouse.gov/omb/inforeg_chap1\#bpabc.

5 See generally Anu Bradford, 'The Brussels Effect' (2012) 107 Northwestern University Law Review 1; Christopher Kuner, 'The Internet and the Global Reach of EU Law,' LSE Law, Society and Economy Working Paper 4/2017. 
mechanisms from their external consequences, which include, for instance, the effect of home-sharing on urban housing policies or the effect of skill- and time-sharing platforms on labour relations. These distinctions must be borne in mind as when it comes to platforms' internal operation standards applying homogenously throughout the internal market are easier to define than in respect of their external consequences where national and subnational actors are, in accordance with competence-division and subsidiarity, often the appropriate scale of regulation.

Our analysis proceeds as follows. We shall first provide an overview of the platform economy and its definitional challenges before venturing on to investigate various regulatory models that have been suggested as possible regulatory avenues. This includes an analysis of command-and-control regulation; self-regulation and co-regulation to determine their suitability in addressing the regulatory challenges inherent to digital data-driven platforms.

\section{THE PLATFORM ECONOMY}

Over the past years new business models centred on data-driven digital platforms emerged in addition to their more senior counterparts GAFA (Google, Amazon, Facebook and Apple). They include most famously the home-sharing platform Airbnb and ride-sharing platform Uber, peer-lending platforms such as Kickstarter and Lending Club, the fashion platforms such as Rent the Runway, but also timeand skill-sharing platforms like Upwork and Taskrabbit, to name just a few. Providing a precise definition of a digital platform is no easy undertaking. This starts with a terminological challenge. The platform economy encompasses various phenomena, which have for example been termed the 'sharing economy', the 'gig economy', the 'mesh economy' and the 'Uberization of everything'. Lobel has rightly observed that 'no term completely captures the entire scope of the paradigmatic shift in the ways we produce, consume, work, finance, and learn'. ${ }^{9}$ Regulators have started crafting legal definitions capable of capturing the diversity of platforms. The French Conseil National du Numérique considers a platform to be a service that provides an intermediary function in the access of information, goods or services that are usually provided by third persons. ${ }^{10}$ The

\footnotetext{
${ }^{6}$ For an overview, see Nestor Davidson, Michèle Finck and John Infrance, Cambridge Handbook of the Law and Regulation of the Sharing Economy (Cambridge University Press 2018).

${ }^{7}$ Lisa Gansky, The Mesh: Why the Future of Business is Sharing (Penguin 2010).

${ }^{8}$ Sunny Freeman, 'Uberization' of Everything is Happening, but not every 'Uber' will succeed, Huffington Post (1 April, 2015), http://www.huffingtonpost.ca/2015/04/01/uberization-uber-ofeverything n $6971752 . h \mathrm{ml}$.

${ }^{9}$ Orly Lobel, 'The Law of the Platform' (2016) 101 Minnesota Law Review 88, 88.

${ }^{10}$ Conseil National du Numérique, 'Ambition Numérique. Pour une Politique Française et Européenne de la Transition Numérique' (2015) 59 ('[u]ne plateforme pourrait être définie comme un service occupant une fonction d'intermédiaire dans l'accès aux informations, contenus, services ou biens, le plus souvent édités ou fournis par des tiers').
} 
European Commission has recently defined a platform as 'an undertaking operating in two (or multi)-sided markets, which uses the Internet to enable interactions between two or more distinct but interdependent groups of users so as to generate value for at least one of the groups'.11 The European Parliament has adopted a different position and considers that 'it would be very difficult to arrive at a single, legally relevant and future-proof definition of online platforms at EU level, owing to factors such as the great variety of types of existing online platforms and their areas of activity, as well as the fast-changing environment of the digital world'.12 It suggested that as a consequence platforms 'should be distinguished and defined in relevant sector-specific legislation at EU level according to their characteristics, classifications and principles'.13 Amidst such definitional challenges it is easier to define the platform by what it is not: conventional, static, and easy to qualify. These characteristics explain why platforms continue to puzzle observes, including regulators.

The key characteristics of the digital economy set it apart from the postindustrial model of recent decades. It can thus be argued that similarly to the economic transformations of the past a new regulatory model is needed to accompany economic shifts. ${ }^{14}$ The current state of affairs is characterised by uncertainty regarding applicable rules that is exacerbated by regulatory fragmentation stemming from divergent regulatory tactics between and within Member States. ${ }^{15}$ Such uncertainty, coupled with ill-suited legal frameworks, risks stifling innovation, a concern that is particularly resonant in the EU, which lags behind Asia and the United States in digital innovation. ${ }^{16}$ In light of regulatory uncertainty and potentially out-dated rules largely fashioned for offline commerce platforms are currently subject to legal categories and regimes that seem illsuited. ${ }^{17}$ Regulatory uncertainty is a double-edged sword that can slow down platforms' development but equally bears the risk of facilitating the uncontrolled

${ }^{11}$ European Commission, 'Public Consultation on the Regulatory Environment for Platforms, Online Intermediaries, Data and Cloud Computing and the Collaborative Economy' (2015) 5,

https:/ / ec.europa.eu/digital-single-market/en/news/public-consultation-regulatory-

environmentplatforms-online-intermediaries-data-and-cloud.

12 Report of the European Parliament on Online Platforms and the Digital Single Market (2016/2276

(INI)), available at: http://www.europarl.europa.eu/sides/getDoc.do?type=REPORT\&reference $=$ A 8 2017-0204\&format $=$ XML\&language $=\mathrm{EN}$.

13 Ibid.

14 For a discussion, see Carlota Perez, Technological Revolutions and Financial Capital: The Dynamics of Bubbles and Golden Ages (Edward Elgar 2002).

15 Report of the European Parliament on Online Platforms and the Digital Single Market (2016/2276

(INI)), http://www.europarl.europa.eu/sides/getDoc.do?type=REPORT\&reference=A8-2017$0204 \&$ format $=$ XML\&language $=\mathrm{EN}$.

${ }_{16}$ In its Communication on Online Platforms, the European Commission could only mention BlaBlaCar and Skyscanner as globally competitive platforms from the EU. 'Communication on Online Platforms and the Digital Single Market' (supra note 3) 3.

17 See also Vassilis Hatzopoulos and Sofia Roma, 'Caring for Sharing? The Collaborative Economy Under EU Law’ (2017) 54 Common Market Law Review 81. 
expansion of platform power. ${ }^{18}$ Platform power is indeed increasingly becoming a cause of concern, also for EU institutions. ${ }^{19}$

Regulators accordingly face no easy task considering the lack of understanding of platforms' very definition, their impact, and also how they operate given that their algorithms and the data they run on are generally proprietary and closed. ${ }^{20}$ The resulting information asymmetry burdens any discussions regarding appropriate regulatory solutions. The platform economy has moreover let to the emergence of hybrid categories unknown to the law, such as 'prosumers' (an individual that is both a provider and a consumer in the platform economy) and blurs established legal categories such as residential and commercial real estate or freelancer and employee. ${ }^{21}$ Platforms themselves have been very vocal as to what they consider regulatory challenges and solutions. A crucial point to note is that the regulatory disruption created by platforms is not an accidental effect of the platform economy but rather a constituent characteristic thereof. ${ }^{22}$

The European Commission's first reaction was one of regulatory reluctance as it is yet to propose concrete legislative proposals. Cauffmann and Smits noted that the most interesting aspect of the Commission's position on platforms is that it is willing to go along with industry claims that these new business models should benefit from the application of less stringent rules. ${ }^{23}$ In the meantime, platforms operate in the ensuing legal vacuum. They do not operate anarchically, however, but rather self-regulate where they are not subject to more dated legal principles. Their development has been largely extra-legal. As pressure to regulate mounts and as judicial challenges accumulate, the Commission will likely have to qualify some regulatory aspects in the not too distant future, including the qualification of regulatory actors.

\footnotetext{
18 On the risks thereof, see Orla Lynskey, 'Regulating "Platform Power"' LSE Law, Society and Economy Working Papers 1/2017. Frank Pascquale, The Black Box Society (Harvard University Press 2015).

${ }^{19}$ See Communication from the Commission to the European Parliament, the Council, the European Economic and Social Committee and the Committee of the Regions, 'A Digital Single Market Strategy for Europe' COM (2015) 192 final, 12 ('[s]ome online platforms have evolved to become players competing in many sectors of the economy and the way they use their market power raises a number of issues that warrant further analysis beyond the application of competition law in specific cases').

20 On this, see generally Frank Pascquale (n 18).

${ }^{21}$ Andy Kessler, 'Brian Chesky: The "Sharing Economy" and Its Enemies', Wall Street Journal, 17 January 2014, https://www.wsi.com/articles/brian-chesky-the-8216sharing-economy8217-and-itsenemies-1390003096.

${ }^{22}$ Elizabeth Pollman and Jordan Barry, 'Regulatory Entrepreneurship' (2017) 90 Southern California Law Review 383.

${ }^{23}$ Caroline Cauffman and Jan Smits, 'The Sharing Economy and the Law. Food for European Lawyers' (2016) 23 Maastricht Journal of European and Comparative Law 903, 907.
} 


\section{REGULATING THE PLATFORM ECONOMY}

It has already been seen above that we must distinguish between the 'who' and the 'how' of platform regulation. In respect of the suitable regulatory actors the Commission has put three distinct options on the table: traditional top-down secondary legislation, self-regulation or co-regulation. This section introduces these three regulatory models and evaluates their applicability to the platform economy. Before venturing on to this task, however, it should be borne in mind that while these denominations point towards various approaches to regulation, they operate on a spectrum. ${ }^{24}$

\section{A. COMmanding-AND-CONTROLLING Platforms}

Online platforms are partly self-regulating entities also caught by existing supranational rules, including consumer protection provisions, the protection of personal data, Articles 101 and 102 TFEU and the fundamental economic freedoms. ${ }^{25}$ As these frameworks mostly pre-date online platforms the question of legislative amendment has emerged which could take the form of modifying existing legal frameworks such as the E-Commerce Directive or create new legislation. ${ }^{26}$ As a preliminary note it should be stressed that where top-down legislation is the preferred option, the subsidiarity argument would point towards harmonized EU legislation, at least regarding platforms' internal operation given that 'there cannot be 28 different sets of rules for online platform in a single market'. ${ }^{27}$

Command-and-control regulation, also referred to as 'top-down' regulation, is what typically comes to mind when thinking about regulating economic behaviour: legislation. It has been defined as 'regulation by the state, which is often assumed to take a particular form, that is the use of legal rules backed by criminal sanctions'. ${ }^{28}$ The EU's regulatory activity is indeed generally associated with secondary legislation crafted under the ordinary legislative procedure. ${ }^{29}$ This echoes that law is traditionally State- or EU-centred, unified, hierarchical and

\footnotetext{
24 Tony Prosser, 'Self-Regulation, Co-Regulation and the Audio-Visual Media Services Directive' (2008) 31 Journal of Consumer Policy 99, 99.

25 Rupprecht Podszun and Stephan Kreifels, 'Digital Platforms and Competition Law' (2016) 5 Journal of European Consumer and Market Law 33;

26 Directive 2000/31/EC of the European Parliament and of the Council of 8 June 2000 on certain legal aspects of information society services, in particular electronic commerce, in the Internal Market OJ L 178/1 (2000).

27 European Commission, 'Communication on Online Platforms and the Digital Single Market' (supra note 3) 4 .

28 Julia Black, 'Decentring Regulation: Understanding the Role of Regulation and Self-Regulation in a "Post-Regulatory" World' (2001) 54 Current Legal Problems 103, 105.

29 Article 294 TFEU.
} 
unpinned by the rule of law. ${ }^{30}$ Regulation should be simple, constant, and predictable and these objectives are conventionally fulfilled through homogenously-applying legislation. EU law, it has been suggested, 'has tended to stand in awe of [the] traditional conception of law'. ${ }^{31}$ This is rooted in the fact that 'not only are those attributes of a traditional conception of law consistent with the ever closer integration motif, but they speak too of power and uncompromising authority, in real as well as symbolic terms, and never is power and authority more desired than when it is contested, as in the case of the EU'.32

In light of the above top-down legislation could appear to be the evident method of platform regulation. It would create uniformity across the Union as the Commission indeed considers that ' $\mathrm{r}$ ] egulatory uncertainty and fragmentation across and within Member States complicates (or even impedes) market access and limits investment opportunities for platforms'. ${ }^{33}$ Numerous characteristics of platforms however provide reason to doubt that secondary legislation would be an effective mode of regulation. First, we must return to the information asymmetry that characterises the platform economy in the absence of reliable information about these black boxes as well as their socio-economic impact. It is true that information gathering always plagues any lawmaker. ${ }^{34}$ This issue is nonetheless particularly salient with respect to the platform economy, as experience remains limited. Legislating despite the prevailing information gap bears three central risks. The adoption of ill-suited principles may firstly stifle innovation, and end up harming platforms and the economy. Second, the rules adopted may not be enforceable or be very burdensome to enforce. ${ }^{35}$ Third, specific platform regulation is often considered to simply add more regulation (especially on consumer protection and e-commerce) where there already is a complex regulatory framework. There are gaps in understanding these autonomous technological systems and that these gaps also affect some of the main actors involved in law making, politicians and civil servants, who often lack the necessary expertise to make sense of the little information that is available about platforms.

It is important to remember that while top-down legislation may be our go-to option it is far from perfect. It facilitates forum shopping, which is far from speculative, considering how early tech firms have incorporated in jurisdictions known for their lenient application of data protection standards. We should be wary of idealizing legislation as always constituting the most advantageous mode of economic regulation. Whereas it is tempting to suggest that it is the most

\footnotetext{
30 Michael Wilkinson, 'Three Conceptions of Law: Towards A Jurisprudence of Democratic Experimentalism' (2010) Wisconsin Law Review 673, 673-4.

31 Joanne Scott and David Trubek, 'Mind the Gap: Law and New Approaches to Governance in the European Union' (2002) 8 European Law Journal 1, 9.

32 Ibid, 10.

${ }^{33}$ Commission Staff Working Document, 'A Single Market Strategy for Europe: Analysis and Evidence', SWD (2015) 202 final, 6.

34 Stephen Breyer, Regulation and its Reforms (Harvard University Press 1984) 109-18.

35 An example would be German cities' attempt to enforce the 'Zweckentfremdungsverbot' that is examined further below.
} 
democratic and legitimate mode of regulation, reality casts doubt on such simplistic statements, particularly so in the context of a supranational law-making process shaped by opaque trilogues. ${ }^{37}$ Top-down regulation furthermore relies on few 'well-educated, specially trained, and publically appointed professionals' 38 leaving little room for polycentric deliberation and compromise. Equally, while we presume that all regulation is designed to enhance the public good we long know that regulation can also be designed to enhance the interests of lobbyist or other entrenched stakes. ${ }^{39}$

The above observations accordingly cast doubt on whether top-down legislation will really enable regulations to moderate between the dilemma of not stifling innovation on the one hand, and not leaving innovative practices unregulated on the other. ${ }^{40}$ We must thus think of other options. De Búrca has shown that two different kinds of impetus mandate reliance on new governance methods as opposed to top-down legislation: strategic uncertainty, defined as complex policy problems that have not 'shown themselves to be readily amendable to resolution whether through hierarchy, market or otherwise' and interdependence 'where divergent regulatory regimes affect one another to varying degrees, creating externalities, giving rise to conflict, or hindering transactional or personal mobility'. ${ }^{41}$ We can readily see that these elements are present in the platform economy characterised by uncertainty and complexity where various systems are in need of alignment. It has equally been suggested that 'the intensity with which a given problem presents may be likely to affect the vitality and success of an experimentalist-governance solution'. 42 While chronic problems may be best addressed by command-and-control legislation, new governance methods are better suited for acute and novel issues that are subject to rapid change such as platforms.

The territorial dimension of the platform economy is particularly salient and must be borne in mind whenever different regulatory options are pondered. On the one hand, platforms don't respect jurisdictions as they spread via the World Wide Web. Similarly, we can at least assume that many elements of their internal functioning are identical notwithstanding where users relying on its intermediary function are located. On the other hand, however, the external effects of platforms diverge dramatically depending on the geographical location at stake and

${ }^{37}$ Giandomenico Majone, 'The Rise of the Regulatory State in Europe' (1994) 17 West European Politics

38 Orly Lobel, 'The Renewal Deal: The Fall of Regulation and the Rise of Governance in Contemporary Legal Thought' (2004) 89 Minnesota Law Review 342, 371.

39 George Stigler, 'The Theory of Economic Regulation' (1971) 2 Bell Journal of Economics and Management 1, 3; Fred McChesney, 'Rent Extraction and Rent Creation in the Economic Theory of Regulation' (1987) 16 Journal of Legal Science 1.

40 See further Sofia Ranchordás, 'Does Sharing Mean Caring? Regulating Innovation in the Sharing Economy' (2015) 16 Minnesota Journal of Law, Science \& Technology 413.

41 Gráinne de Búrca, 'New Governance and Experimentalism: An Introduction' (2010) Wisconsin Law Review 227, 232

42 Ibid, 233. 
different policies may be appropriate for different cities within the same country, and sometimes even different areas of the same city. ${ }^{43}$ Supranational secondary legislation is hence both under-inclusive and over-inclusive given that it catches both too wide and too narrow a net. Concluding that top-down legislation risks constituting an unsuitable method of regulating platforms we now turn to the alternatives, starting with self-regulation.

\section{B. Self-Regulating Platforms}

Platforms are already self-regulating entities. They determine the terms and conditions of their intermediary function and define online and offline standards of behaviour. Platforms commonly argue that they should be free from any outside interference and entirely govern themselves considering that they have more knowledge and better enforcement mechanisms than public authorities. This section introduces the regulatory model underlying such claims and tests its application to digital data-driven platforms.

\section{The Notion of Self-Regulation}

In the EU context, self-regulation has been defined as 'the possibility for economic operators, the social partners, non-governmental organisations or associations to adopt amongst themselves and for themselves common guidelines at European level (particularly codes of practice or sectoral agreements)'. ${ }^{44}$ According to Black self-regulation 'describes the situation of a group of persons or bodies, acting together, performing a regulatory function in respect of themselves and others who accept their authority." 45 This is distinguished from 'individualised regulation', which is 'regulation which is tailored to the individual firm'. ${ }^{46}$ Given that current debates concerning the platform sector understand selfregulation as regulation for the individual platform, which reflects that they already are their own de facto independent standard-setter, we will use the notion of selfregulation to also include individual regulation.

Self-regulation can take a number of forms as it can be mandated by public authorities or adopted voluntarily. Similarly the incentives for self-regulation vary as it can echo an attempt to operate under set internal standards, align industry behaviour, or counter threats of statutory intervention by public authorities. Selfregulation is far from being a novel phenomenon as it has long been relied on in complex sectors such as nuclear energy and finance, confirming its suitability in

\footnotetext{
${ }^{43}$ In the U.S., the city of New Orleans for instance has different rules on short-term rentals depending on the area at stake. See further https://www.nola.gov/short-term-rentals/.

${ }^{44}$ Interinstitutional Agreement on Better Law-Making (2003) OJ C 321, para 22.

${ }^{45}$ Julia Black, 'Constitutionalising Self-Regulation' (1996) 59 Modern Law Review 24, 27.

46 Ibid, 27.
} 
contexts of complexity. ${ }^{47}$ Self-regulation has similarly been relied on to regulate the professions, such as through Bar Associations. This section highlights the selfregulatory nature of prominent sharing economy platforms and looks towards the future in enquiring whether self-regulation constitutes an adequate long-term regulatory option. While this essay focuses on platforms themselves it must be stressed that current economic shifts will test self-regulation also in ancillary domains, including but not limited to the self-regulation of the relatively new profession of the 'data scientist'.

Before venturing on to the examination of self-regulating platforms, we should stress that as a general matter technology is a de facto self-regulating force, best exemplified by Lessig's maxim of 'code is law' that reflects that often code, not law, reflects what individuals can and cannot do. 48 This has been confirmed in many respects, including data protection $\mathrm{law}^{49}$ and is today proven true by the centrality of platforms' algorithms as governance actors. It can indeed not be denied that platforms have become the relevant 'rule-makers'. ${ }^{50}$ Nonetheless, the fact that code acts as law does not mean that it should operate independently of law. We now move to discuss curtrent examples of self-regulation.

\section{Examples of Self-Regulation}

Platforms can be understood as self-regulating systems that act independently but also in collaboration with other platforms to establish industry standards. It has been suggested that 'the Internet, and the rapid growth of the sharing economy, alleviates the need for much of this top-down regulation, with these recent innovations likely doing a much better job of serving consumer needs'. ${ }^{51}$ This for instance occurs through regular meetings where platforms discuss issues of trust, safety and security. ${ }^{2}$ This has led some to compare platforms to governments as 'like governments, each platform is in the business of developing policies which enable social and economic activity that is vibrant and safe'. ${ }^{33}$ Given that little is known about the frequency, form and outcome of such meetings, this section

\footnotetext{
${ }^{47}$ Neil Gunningham and Joseph Rees, 'Industry Self-Regulation: an Institutional Perspective' (1997) 19 Law \& Policy 363. Elizabeth Howlett et al, 'The Role of Self-Regulation, Future Orientation and Financial Knowledge in Long-Term Financial Decisions' (2008) 42 Journal of Consumer Affairs 223.

${ }^{48}$ Lawrence Lessig, Code and Other Laws of Cyberspace (Basic Books 1999) (hereafter 'Lessig, Code and other Laws of Cyberspace')

49 Agustín Rossi, 'Internet Privacy: Who Sets the Global Standard?' (2014) 49 Italian Journal of International Affairs 65

50 Marta Cantero Gomito, 'Regulation.com. Self-Regulation and Contract Governance in the Platform Economy: A Research Agenda' (2017) 9 European Journal of Legal Studies 53 (hereafter 'Cantero, Regulation.com').

${ }^{51}$ Christopher Koopman et al. 'The Sharing Economy and Consumer Protection Regulation: The Case for Policy Change' (2014) Mercatus Working Paper, 1 https://www.mercatus.org/publication/sharingeconomy-and-consumer-protection-regulation-case-policy-change.

${ }^{2}$ Nick Gossman, White Paper: Regulation, the Internet Way. A Data-First Model for Establishing Trust, Safety, and Security (2015) http://datasmart.ash.harvard.edu/news/article/white-paper-regulation-theinternet-way-660. (hereafter 'Gossman, Regulation the Internet Way').

${ }^{53} \mathrm{Ibid}$.
} 
focuses on the information that is available in respect of platforms regulating themselves. The key argument that has been advanced in favour of self-regulation is information asymmetry as most information regarding platforms' functioning and impact is at the exclusive disposal of platforms themselves. There is a tendency for the industry to argue that when it comes to regulation 'the answer is in the data' yet only platforms have access to operational data, which not only is secret but also susceptible to, in some at least jurisdictions, benefit from trade secret protection. ${ }^{54}$

The Commission's reluctance to legislate has been linked to a more general move towards a post-regulation society. ${ }^{55}$ Aspects of platforms' intermediary function are indeed mostly shaped by internal rather than legislative standards. Uber's Community Guidelines are a case in point. The platform's code of conduct regulates the respective behaviour of riders and drivers and requires mutual respect and common courtesy such as 'not to shout, swear or slam the car door'. 56 Beyond such hopefully obvious behavioural guidelines the platform has also established principles of a more controversial nature such as the 'no sex rule' pursuant to which there should be 'no sexual conduct between drivers and riders, no matter what, phrased as an intention to not only apply during the ride, but generally (i.e. preventing rider and driver from arranging a subsequent date followed by sexual intimacy). ${ }^{57}$ The Uber Community Compact also addresses safety, providing that passengers buckle up and prohibits guns, even in jurisdictions where carrying a gun is per se legal.58 While Uber doesn't allow minors to use others' accounts it has created 'Teen accounts' in some cities. ${ }^{59}$ This illustrates that platform self-regulation can easily be fashioned to enable algorithmfacilitated regulatory fragmentation depending on location.

Platform self-regulation comes with its own enforcement mechanism. In the United States Uber sanctions non-respect of its internal rules by delisting the driver or rider. Riders are delisted where they damage property, hurt someone or engage in flirting or sexual contact with drivers or fellow riders; where inappropriate or abusive language or gestures are used; where unwanted contact occurs after the drive or where local laws are broken. ${ }^{60}$ It is apparent that the platform imposes rules beyond those created by the legal framework that are incentivised by the market and public relation concerns and tailored to increase trust in the platform.

\footnotetext{
${ }^{54}$ Gianclaudio Malgieri, 'Trade Secrets v Personal Data: A Possible Solution for Balancing Rights' (2016)

6 International Data Privacy Law 102.

${ }_{55}$ Cantero, Regulation.com (n 49) 53.

56 https://www.uber.com/de/legal/community-guidelines/us-en/.

${ }^{57}$ Ibid. (emphasis added).

${ }^{58}$ Ibid.

${ }^{59} \mathrm{Ibid}$.

${ }^{60} \mathrm{https}$ // www.uber.com/de/legal/community-guidelines/us-en/.
} 
Platform self-regulation can also be mandated by public authorities. California adopted a self-regulatory response to ride-sharing platforms with the creation of Transportation Network Companies ('TNCs') whereby public authorities define standards that drivers of smartphone-based point-to-point urban transportation vehicles must conform to. ${ }^{61}$ Enforcement responsibility is delegated to the platforms themselves. ${ }^{62}$ This amounts to 'coerced self-regulation' whereby industry formulates rules under the threat of governmental regulation. ${ }^{63} \mathrm{~A}$ further example of self-regulation can be observed in respect of the global free-lancing platform Upwork. ${ }^{64}$ The platform imposed a 'minimum rate' for all work contracted via its intermediary function, notwithstanding which corner of the world it is being performed in, of $\$ 3$ per hour. ${ }^{65}$ While this appears to be an incredibly low sum, the imposition of the minimum rate itself is an intriguing example of self-regulation, especially when contrasted with many jurisdictions that do not have minimum wage provisions. The policy highlights the potential for platforms to in principle determine such standards, which can then be automatically enforced through the platform's algorithm much more straightforwardly than public authorities can. Code is, unlike any other normative systems, self-executing and can govern behaviour easily, which is probably the strongest argument in favour of self-regulation.

Technology governs online spaces, famously captured by the 'code is law' maxim. ${ }^{66}$ Code creates binding rules that may be known to all, but moreover has an enormous potential to nudge individuals into adopting a certain behaviour. Uber has been said to be engaged in an extraordinary behind-the-scenes experiment in behavioral science to manipulate [its drivers] in the service of its corporate growth' most notably through psychological inducements to influence when, where and how they work. ${ }^{67}$ Under a model of pure self-regulation code regulates behaviour unrestrictedly. We should moreover be careful to not mistake code as merely regulate online behaviour as it increasingly governs offline behaviour through online standards, a phenomenon likely to dramatically increase with the advent of the Internet of Things.

\section{Assessment}

Self-regulation has, unsurprisingly, attracted wide support from industry insiders. Gossman, a general manager at the venture capital firm Union Square Ventures

\footnotetext{
${ }^{61}$ Rebecca Elliott, 'Sharing App or Regulation Hack(ney)?: Defining Uber Technologies, Inc.' (2016) 41 Journal of Corporation Law 727.

62 Ibid.

63 Julia Black, 'Decentring Regulation: Understanding the Role of Regulation and Self-Regulation in a "Post-Regulatory" World' (n 28) 118.

64 https://www.upwork.com.

65 https://support.upwork.com/hc/en-us/articles/211062988-Minimum-Hourly-Rates.

66 See 'Lessig, Code and other Laws of Cyberspace' (n 51).

67 https://www.nytimes.com/interactive/2017/04/02/technology/uber-drivers-psychological-

tricks.html?_r=0.
} 
advocates a 'Regulation 2.0' model that juxtaposes the 'bureaucracy, friction and permission' of current regulatory paradigms with the 'transparency, accountability and innovation' of 'Regulation 2.0'.68 At present access restrictions such as licenses ensure policy goals and enforcement and accountability are expensive and burdensome. The 2.0 model would relax market access and employ ex-post evaluation mechanisms to inspect 'large volumes of real-time data to hold actors accountable'. ${ }^{69}$ Many platforms are however likely to oppose the sharing of large quantities of behaviour-revealing data with public authorities. While such datasharing must be considered as a useful component of platform regulation it has to be noted that no such mechanisms are currently in place, underlining that by and large platforms self-regulate without any external checks.

Self-regulation has also attracted support in academia, most vocally through Sundararajan. Traditionally, government intervention has served to establish trust in market transactions. Sundararajan stresses that platforms now dispose of their own trust-enforcing mechanisms, most obviously peer-review mechanisms that can fulfil that same function more efficiently. ${ }^{70}$ Self-regulation through code is moreover considered to more easily being able to distinguish between various scenarios such as full-time or large-scale professional providers and smaller, semiprofessional providers. ${ }^{71}$ Ogus moreover considers that there is a public interest justification for self-regulation if three conditions are fulfilled: 'first, that the activity is afflicted by some form of market failure, notably externalities or information asymmetries; secondly, that private law instruments are inadequate or too costly to correct the failure; and, thirdly, that self-regulation is a better (cheaper) method of solving the problem than conventional public regulation'.72 While these conditions appear prima facie present in the platform economy context we must nonetheless be careful about giving in to this option too readily.

It can hardly be denied that there are convincing arguments to apply alternative regulatory paradigms to the digital platform economy. Yet regulators should not be overly impressed by platforms' claims to distinctiveness and the resulting unsuitability of other regulatory paradigms. We should not encourage platforms' transformation into purely self-regulating oligopolies that act outside of any oversight mechanisms. Isolated self-regulation not only lacks transparency but moreover fails to account for the interests of actors other than the platform itself. It moreover risks being put to the side when problems actually arise. Indeed, while we have observed above that Uber wants to prevent sexual contact between drivers and riders, it it repeatedly acted in grossly unacceptable ways when faced

\footnotetext{
68 'Gossman, Regulation the Internet Way' (n 55).

${ }^{69} \mathrm{Ibid}$.

${ }^{70} \mathrm{Ibid}, 141$

${ }^{71}$ Ibid.

72 Anthony Ogus, 'Rethinking Self-Regulation', in Robert Baldwin, Colin Scott and Christopher Hood (eds) A Reader on Regulation (Oxford University Press 1998) 374.
} 
with cases of sexual assault and rape. ${ }^{73}$ This highlights the biased incentives platforms have in respect of policing themselves. Fearing public opinion backlash platforms may chose to protect their own image rather than stick to principle. Further, where self-regulation applies there is a need for counterbalances that safeguard public interests. Regarding data access and ownership, an issue residing at the core of platforms' operation, the Commission considers that any principled openness towards sector-specific regulation should account for power imbalances impacting on negotiating power as market-based solutions alone are not sufficient 'to ensure fair and innovation-friendly results, facilitate easy access for new market entrants and avoid lock-in situations'. ${ }^{74}$ While we may welcome Upwork's introduction of a minimum rate and the ease with which it can be enforced we can also perceive why we would prefer for the platform to determine rate levels not in isolation but rather collaboratively with public authorities and other interest groups.

We must at this stage return to the theme of information asymmetries. While it is doubtlessly true that platforms themselves own myriads of data that regulators lack access to, they do not have an overview of all the information required to make regulatory decisions. Indeed, while it is often assumed that industry has all the knowledge and public authorities have none, oftentimes 'no single actor has all the knowledge required to solve complex, diverse, and dynamic problems, and no single actor has the overview necessary to employ all the instruments needed to make regulation effective'. ${ }^{75}$ Specifically with respect to platforms we may argue that while Airbnb has considerably more data points regarding home-sharing in a given city, and can more easily enforce a, say, 30-day limit for home-sharing through its algorithm, the city and its residents are in a more adequate position to determine whether and to what extent home-sharing should be limited in light of its unique housing situation and preferences.

Furthermore, while it is hard to deny that internal rating-mechanisms and peer-review options are fascinating trust-enforcing mechanisms that impact on the need for State-intervention in at least some respects we simply don't know enough about them to allow them to replace public safeguards. ${ }^{76}$ There is a continuing lack of insight into the functioning of rating mechanisms and further research from

\footnotetext{
${ }^{73}$ In the UK, Uber has for instance been accused of not reporting sexual assault committed by one of its driver while riding for the platform, allowing the driver to strike again thereafter. See Press Association, 'Uber failing to report Sex Attacks by Drivers, Says Met Police' The Guardian (13 August 2017) https://www.theguardian.com/technology/2017/aug/13/uber-failing-to-report-sex-attacks-by-

drivers-says-met-police. In another case, Uber executives in this case obtained and mishandled the victim's medical records. See further Mike Isaac, 'Uber is sued by Woman who was raped by one of its Drivers in India'. New York Times (15 Juen 2017) https://www.nytimes.com/2017/06/15/technology/uber-india-rape-lawsuit.html?mcubz=1

${ }^{74}$ European Commission, 'Building a European Data Economy'Com (2017) 9 final, 10.

75 Julia Black, 'Decentring Regulation: Understanding the Role of Regulation and Self-Regulation in a "Post-Regulatory" World" (n 28) 107.

${ }^{76}$ The regulatory dimension of trust and reputation mechanisms is also usefully discussed by Marta Cantero Gomito (n 49).
} 
behavioral psychology and management is imperative. From the perspective of EU law, it must moreover be stressed that there is a risk that platform selfregulation breaches competition law. ${ }^{77}$ The absence of uniform regulatory standards under self-regulatory models can moreover result in case-by-case litigation to determine applicable rules, which is undesirable for both platforms but also the regulator. ${ }^{78}$

Even critics of regulation argue that 'a disembodied free market, one which does not rest upon government force, will function effectively is certainly a mistake of epic proportions, is not an anarchist myth'.79 A purely self-regulatory approach moreover risk increasing platform power, which is already an increasing concern. ${ }^{80}$ Platforms which we still tend to think of as disruptive innovators that can just as quickly be replaced by the next disruptive idea have long become incumbents. This realization is critical as if online platforms are left to self-regulate their industry free from outside interference there is a risk that they act on their interest in heightening regulatory barriers in order to prevent the market entry of competitors.

We thus conclude that while there are arguments in favour of alternative regulatory solutions adapted to the digital economy pure forms of self-regulation are undesirable. This leads us to examine co-regulation as an alternative.

\section{Co-Regulated Platforms}

The above sections have identified pertinent reasons why command-and-control and self-regulation present considerable disadvantages. We thus continue our search for an appropriate regulatory paradigm by looking towards co-regulation. In the EU context, co-regulation has been defined as a 'mechanism whereby an [EU] legislative act entrusts the attainment of the objectives defined by the legislative authority to parties which are recognized in the field (such as economic operators, the social partners, non-governmental organizations, or associations)'. ${ }^{81}$ EU legislation accordingly sets out objectives to be attained but their achievement is entrusted to non-public actors in economic and social domains, which appears to imply that the method is considered suitable for economic and social regulatory objectives. While the EU is seldom seen to overtly embrace co-regulatory

\footnotetext{
${ }^{77}$ For a discussion, see Imelda Maher, 'Competition Law and Transnational Private Regulatory Regimes: Marking the Cartel Boundary' (2011) 38 Journal of Law and Society 119. For this to be the case there would need to be coordination between different would-be competitor platforms that limits competition between them.

${ }^{78}$ Edward Glaeser and Andrei Shleifer, 'The Rise of the Regulatory State' (2003) 41 Journal of Economic Literature 401, 402-03.

79 Richard Epstein, 'Can Technological Innovation Survive Government Regulation?’ (2013) 36 Harvard Journal of Law and Public Policy 87, 88.

${ }^{80}$ Orla Lynskey (n 18).

812003 Interinstitutional Agreement on Better Law-Making, (n 43) para 18.
} 
solutions Sabel and Zeitlin have shown that the Union in fact often relies on framework goals that lower units are then given freedom to achieve. ${ }^{82}$ This essay suggests that a more sophisticated version of co-regulation, which entrusts not just the Union and platforms, but is rather fashioned in a polycentric manner through the additional involvement of other stakeholders, as the most appropriate regulatory response to the platform economy.

Co-regulation denotes various regulatory phenomena that have in common that 'the regulatory regime is made up of a complex interaction of general legislation and a self-regulatory body' ${ }^{83}$ It thus encompasses hybrids that do not meet the 'administrative and statute-based legitimacy of regulation, yet clearly perform some elements of public policy more than self-regulation' ${ }^{84}$ In essence, this regulatory solution creates collaboration between public authorities and private bodies to regulate private activity while accounting for its particularities and safeguarding public policy objectives. Acknowledging the complex interaction between the State, the market, and increasingly also technology, co-regulation reflects the spirit of new governance approaches that recognize the benefits to including a broader pool of stakeholders and decision makers in the articulation, execution and evolution of policy, law, norms development, oversight and regulation'. ${ }^{85}$ Co-regulation has also been referred to as 'regulated self-regulation' emphasizing the interplay between the regulator and the regulated. 86

It is important to bear in mind that co-regulation does not amount to deregulation. Public authorities are involved at all stages of the process from the definition of the legislative framework to the complex review mechanisms. Indeed, in order for co-regulation to work, it must not only be accompanied by regular evaluations and reviews, but in addition 'command-and-control regulation must exist as a possibility in the background in the event of the failure of self-regulation so that important objectives can still be achieved and enterprises are motivated to co-operate. 87

\section{Examples of Co-Regulation}

While the EU is maintaining its wait-and-see approach a number of co-regulatory solutions have been adopted at subnational level in various Member States. We focus on agreements between national regulators and home-sharing platforms, as they are to date the most paradigmatic example in this context. Airbnb and

\footnotetext{
82 Charles Sabel and Jonathan Zeitlin, 'Learning from Difference: The New Architecture of Experimentalist Governance in the EU' (2008) 14 European Law Journal 271, 273.

83 Christopher Marsden, Internet Co-Regulation (Cambridge University Press 2011) 46

84 Ibid, 211.

85 Raymond Brescia, 'Regulating the Sharing Economy: New and Old Insights into an Oversight Regime for the Peer-to-Peer Economy' (2016) 95 Nebraska Law Review 87, 134.

86 See Wolfgang Hoffmann-Riem, Verwaltungsrechtsreform - Ansätze am Beispiel des Umweltschutzes, in Wolfgang Hoffmann-Riem et al (eds), Reform des Allgemeinen Verwaltungsrechts - Grundfragen (BadenBaden 1993) 115, 140. See also Wolfgang Schulz and Thorsten Held (n 36).

87 Wolfgang Schulz and Thorsten Held (n 15) 63.
} 
Amsterdam have signed a memorandum of understanding designed to 'promote responsible home sharing' that introduces automated limits to ensure that entirehome listings are not shared for more than sixty days. ${ }^{88}$ Similar models have been adopted in other European cities such as London where this agreement encompasses a 90-day period..$^{89}$ Beyond the determination of local time-limits enforced by platforms, arrangements have reached concerning tax-collection. In Lisbon Airbnb collects tourist tax on behalf of hosts. ${ }^{90}$ In France, Airbnb has concluded agreements with nineteen cities pursuant to which it collects tourist taxes on behalf of them. ${ }^{91}$ Between October and December 2015 it had collected 1,2 million Euro of fiscal income in Paris alone. ${ }^{92}$

Some platforms have shown a general openness towards such solutions. Airbnb's 'Community Compact' sets out guiding principles to develop partnerships with cities. ${ }^{93}$ It announces that the platform is open to working with cities on a case-by-case basis, accepting different rules for the city in question, including tax-collection on behalf of local governments. ${ }^{94}$ Airbnb considers that in '[w]orking together, platforms like Airbnb can help governments collect millions of dollars in hotel and tourist tax revenue at little cost' 95 and 'provide data to local policymakers to enable smarter decision-making about home sharing rules without compromising hosts' or guests' privacy rights'. ${ }^{96}$ The formalities of such data sharing presently remain exclusively regulated by the platform itself - maintaining a stance of self-regulation in this respect. ${ }^{97}$ We return to this theme just below.

A pivotal argument for involving platforms in regulation is that many regulatory objectives can be fulfilled much more efficiently through their involvement. Airbnb can simply program its algorithm to collect tourist tax whereas we know that ensuring tax compliance is a costly a burdensome task for public authorities, too often qualified by limited success. Much has already been said about the centrality of trust and peer-review mechanisms as a variant of technological regulation. It is however important to remember that these mechanisms serve regulatory functions beyond peer-review, including the verification and digitalization of official identification documents and institutional membership data. This highlights that governments de facto no longer have the exclusive capacity to function as intermediaries mediating the relationship between economic and social actors. Co-regulation forms part of a general evolution from top-down State regulation to participatory models of rule making, compliance and

\footnotetext{
${ }^{88}$ http://www.dutchdailynews.com/amsterdam-airbnb-announce-new-unique-agreement/.

89 Ibid.

90 Ibid.

${ }^{91}$ https://paris.airbnbcitizen.com/fr/airbnb-simplifie-la-collecte-de-la-taxe-de-sejour-dans-19-villes-en-

france/

92 Ibid.

93 https://www.airbnbcitizen.com/the-airbnb-community-compact/.

${ }^{94}$ Ibid.

${ }^{95}$ https://www.airbnbcitizen.com/introducing-the-airbnb-policy-tool-chest/.

${ }^{96}$ Ibid.

${ }^{97}$ https://www.airbnbcitizen.com/airbnb-policy-tool-chest/.
} 
enforcement in which subnational and non-State actors intervene. ${ }^{98}$ While it doesn't replace the EU in its legislative function, the Union transitions from a monopolistic regulator to a regulative facilitator. ${ }^{99}$ Co-regulation also impacts the role of other actors, such as courts, which are no longer the pivotal centre of accountability and blurs the distinction between law-making and the application of law. In light of these various characteristics co-regulation appears are the most suitable regulatory paradigm for the early days of the sharing economy.

\section{The Case for Co-Regulation}

Scott and Trubeck consider that where a number of characteristics are present new governance approaches such as co-regulation are more suitable than command-and-control regulation. These include, firstly, increasing complexity under conditions of uncertainty; secondly the irreducible diversity of the phenomenon, which do not allow for uniform solutions and, thirdly, competence creep. 100 As the implications of the platform economy continue to puzzle observers, it is difficult to imagine unitary rules applying to highly diverse platforms, especially given that the boundaries of EU competence are challenged. Indeed, looking towards home-sharing platforms such as Wimdu, Homeaway or Airbnb we can easily see the desirability of uniform rules governing their internal market aspects yet also see the limits of EU regulation concerning urban housing policy. In this context we may also add the geographical divide between Member States on digital policy, exemplified by the Northern Data Framework. ${ }^{101}$

It is crucial to note that co-regulation is not a one-point intervention but rather an on-going process, making it an experimental learning process that embraces uncertainty and is designed to adapt over time. Tools can be quickly adjusted to new situations, information is constantly gathered and divergent interests are reconciled. One of co-regulation's essential features is that the standards that are defined are constantly evaluated and reviewed. ${ }^{102}$ It is as such particularly well suited to a novel and paradigm-changing phenomenon, especially where assessment is facilitated by big data analysis, which allows for real-time evaluations of regulatory goals. The fact that unlike top-down legislation coregulation involves constant dialogue, assessment and reviews creates informational and adaptability advantages that not only relate to economic rationales but can also be harnessed to achieve public goods.

\footnotetext{
${ }^{98}$ See with respect specifically to the sharing economy Michèle Finck and Sofia Ranchordás, 'Sharing and the City' (2016) 49 Vanderbilt Journal of Transnational Law 1299; Joanne Scott and David Trubek, 'Mind the Gap: Law and New Approaches to Governance in the European Union' (2002) 8 European Law Journal 1.

${ }^{99}$ Christoph Möllers, 'European Governance: Meaning and Value of a Concept' (2006) 43 Common Market Law Review 313, 313 ('governance is a version, a modification or a complement of a classic State government rather than its successor').

100 Joanne Scott and David Trubek (n 31), 8.

101 Aleksandra Eriksson, Nordic and Baltic Countries Step up Digitalisation Efforts, EU Observer, 26 April 2017, https://euobserver.com/nordic/137682.

102 Wolfgang Schulz and Thorsten Held (n 36).
} 
When debating the benefits of co-regulation we must first note that in an age of de facto self-regulation, co-regulation would enable States and the EU to re-enter the debate and ensure that public policy objectives are complied with. While coregulation has elements of 'non state law' it is backed by robust government involvement through the definition of the corresponding legislative framework and review processes. ${ }^{103}$ It is in this respect worth noting that the General Court has also already established in UEAPME that co-regulation is only legitimate where the 'representativeness' of the relevant stakeholders is given. 104 Coregulation should indeed not be understood as the deregulation of public interests as the legislative framework guiding co-regulatory conversations can see to this effect. ${ }^{105}$

The second argument in favour of a co-regulatory approach is that of information asymmetry. Platforms are data monopolies and regulators lack the necessary data points to make informed decisions. Max Weber alerted us that 'those who continuously participate in the market intercourse with their own economic interests have a far greater rational knowledge of the market and interest [in the] situation than the legislators and enforcement officers whose interest is only ideal'. ${ }^{106}$ Involving public and private actors, co-regulation can be seen as offering either the best or the worst of command-and-control and self-regulation. Choosing an optimistic approach, co-regulation can bear the promise of better norms created through compromise that facilitate innovation and experimentation while safeguarding public policy concerns. ${ }^{107}$ We must acknowledge that policymakers frequently simply do not dispose of the required skillset to engage with these phenomena. The involvement of private actors ensures that regulation is 'reflexive', that is to say formulated in a way understood by the autonomous social systems it regulates. ${ }^{108}$ The involvement of private actors in the regulatory process should indeed not automatically been seen as pejorative. Pursuant to Minow '[p]rivatization stimulates new knowledge and infrastructure by drawing new people into businesses previously handled by government'.109 Through coregulatory solutions the interests of the objects of regulation are not eclipsed but form a central part of the regulatory concept. Schulz and Held have stressed that this 'makes information-gathering easier, mainly because the players in the

\footnotetext{
${ }^{103}$ Hanneke van Schooten and Jonathan Verschuuren, International Governance and Law: State Regulation and Non-State Law (Edward Elgar 2008), 2.

${ }_{104}$ Case T-135/96, UEAPME v Council [1998] EU:T:1998:128.

105 On the notion of public interest in the context of regulation, see Mike Feintuck, 'Regulatory Rationales Beyond the Economic: In Search of the Public Interest', in Robert Baldwin, Martin Cave, and Martin Lodge (eds) The Oxford Handbook of Regulation (Oxford University Press 2010).

${ }^{106}$ Max Weber, On Law in Economy and Society 39 (Max Rheinstein \& Edward Shils trans. 1954).

107 Co-regulated has also been advocated in the United States. Bryant Cannon and Hanna Chung, 'A Framework for Designing Co-Regulation Models Well-Adapted to Technology-Facilitated Sharing Economies' (2014) 31 Santa Clara High Technology Law Journal 23.

108 Günther Teubner, Justification: Concepts, Aspects, Limits, Solutions”, in Robert Baldwin et al, A Reader on Regulation (Oxford University Press 1998), and Günther Teubner, Law as an Autopoetic System (Oxford University Press 1993).

${ }^{109}$ Martha Minow, Partners, not Rivals: Privatization and the Public Good (Beacon Press 2003) 1245.
} 
regulatory field (such as economic enterprises) are informed at first hand of ongoing developments. ${ }^{\prime 10}$ Information asymmetry hence makes a clear point in favour of co-regulation.

An additional argument is that of flexibility, which can take numerous forms. First, it is difficult to imagine a legislative solution that could apply to all platforms and all transactions on a given platform whether they be $\mathrm{P} 2 \mathrm{P}$ or B2B. With respect to the so-called sharing economy flexible approaches would moreover allow regulation to distinguish between practices of true sharing and those merely denominated as such, which are often enabled by the same platform. ${ }^{111}$ The platform ecosystem is composed of very diverse players and co-regulation makes it easier to incorporate the flexibility needed to address variegated scenarios. Second, flexibility is necessary to keep up with the pace of change. Innovation has always challenged regulators yet it has usually affected society as a slower pace (think about the new manufacturing processes that initiated the first industrial revolution) whereas the digital data-driven platform economy leaves regulators very little time to learn and adapt. As technology changes and experience grows regulation must be adapted, which highlights the value of regulatory experimentalism in this fast-changing and diverse industry. ${ }^{112}$ Co-regulation, with its continued assessments and reports, can identify best practices and stimulate mutual learning. The Commission has recognised the value of regulatory experimentation in respect of data accessibility and advocates sector-specific experiments on standards. ${ }^{113}$ Specifically with respect to platforms, it has also encouraged public authorities to 'pilot innovative regulatory approaches to verify the feasibility and sustainability of innovative solutions' in light of their complexity and changing nature. ${ }^{114}$

Co-regulation moreover allows for the reconciliation of stark centralizing and decentralizing forces that characterize the platform economy. There are indeed convincing arguments in favour of EU legislation accounting for the internal market rationale but also against it given that regulators should keep the ability to regulate phenomena in light with their respective particularities. The Commission considers that 'there cannot be 28 different sets of rules for online platforms in a single market'. 115 Yet, on the other hand it is hard to envisage a one-fit all solution given the diversity of platforms that have emerged and their often variegated impact across and within Member States. The external consequences of platforms,

\footnotetext{
110 Wolfgang Schulz and Thorsten Held (n 15) 15.

111 On this distinction and its regulatory relevance, see Michèle Finck and Sofia Ranchordás (n 95).

112 See Sofia Ranchordás, 'Innovation Experimentalism in the Age of the Sharing Economy' (2015) 19 Lewis \& Clark Law Review 871.

113 European Commission, 'Building a European Data Economy' (n 72) 17.

114 Communication from the Commission to the European Parliament, the Council, the European Economic and Social Committee and the Committee of the Regions Upgrading the Single Market: More Opportunities for People and Business, COM (2015), 28.10.2015.

115 See also European Commission, Communication on Online Platforms and Digital Single Market, (n 3) 4
} 
such as their impact on urban policy, cannot be addressed in a homogenous manner but rather must allow for geographical variation. Under a co-regulatory approach standards can be determined at EU level but national and subnational actors remain free to determine the precise contours thereof in collaboration with the platform.

Finally co-regulatory solutions offer an ease of enforcement that cannot be achieved under top-down legislation. We have already observed above that where home-sharing platforms have co-regulated in collaboration with local governments, platforms themselves have been entrusted with the enforcement of the resulting policies in the context of their intermediary function. It cannot be ignored that platforms can, through a simple twisting of code, secure that prosumers pay taxes and comply with time-limits. Regulators need to invest considerably more effort and money into to ensure compliance, often with much lower rates of success. An example serves to make this point. Munich, a city faced with rapid expansion and short housing supply, prohibits that residential space be continuously used for commercial purposes such as vacation rental.116 In the absence of any agreement with home-sharing platforms, it policies this policy itself and has hired a number of staff to specifically do so. This has however had a very limited success as in 2015 only a handful of actors breaching this prohibition could be identified, out of an estimated 4000 in total. ${ }^{117}$

From the perspective of platforms, the benefits of engaging in co-regulatory efforts are self-evident. While it leaves them less autonomy than self-regulation, co-regulation nonetheless allows intermediaries to evade command-and-control regulation. Beyond their seat at the table, engagement in such processes can benefit their image and enhance trust in the platform. Co-regulation can focus on outcomes rather than process, meaning that public authorities define the objectives to be achieved through standards rather than precise legal rules, leaving platforms to decide how to best achieve them, encouraging flexibility and adaptability, and, providing room for manoeuvre to platforms.

Returning to the distinction between platforms' internal operation and their external consequences, we conclude that co-regulation presents useful advantages for both contexts. Regarding platforms' internal regulation it is clear that they have most information concerning their operation and are in the best position to implement EU standards on, say, consumer protection. Turning to their external consequences we can equally perceive that co-regulation proves helpful as it allows actors other than the EU to define policies in conjunction with platforms, as illustrated by the collaborations between home-sharing platforms and local governments highlighted above. The information platforms have is thus existential to any co-regulatory approach. Access to such information is likely to prove to be the most delicate aspect of co-regulatory approaches.

\footnotetext{
116 Zweckentfremdungsverbot.

117 http://www.sueddeutsche.de/muenchen/mietmarkt-strafe-fuer-zweckentfremdung-von-wohnungensoll-verzehnfacht-werden-1.3349371.
} 


\section{Data-Sharing as a Quid pro Quo of Co-Regulation}

We have already observed that information asymmetry is a key consideration of platform regulation. Platforms' algorithms are 'black boxes' and the big data they run on is proprietary and closed. ${ }^{118}$ Whereas intermediaries have full knowledge of their internal operation, regulators are largely left to guess. Co-regulation accordingly has to provide for some variant of data sharing to allow regulators to acquire the necessary information and determine whether platforms enforce the determined standards. The treatment of personal and non-personal data however remains one of the most contentious topics in the digital economy and platforms are likely to show reluctance to share data, considering that it is their most valuable asset. While questions of data ownership and access are a sensitive topic with a much broader significance to the digital economy this section merely provides a cursory overview of the stakes at hand. It is however worth noting from the outset that the closed nature of platforms' operation is likely to come under increased scrutiny as the European Parliament has recently called for more transparency in respect of platforms' algorithms. ${ }^{119}$

An agreement concluded between Milan and Airbnb illustrates that datasharing can form an integral part of a regulatory solutions under which a platform is tasked with enforcing rules. Milan and Lombardy approved rules that allow local residents to share their homes via Airbnb but required that, as a counterpart, the platform provide support for major events; help increase digital literacy of seniors; and share data. ${ }^{120}$ Little is known concerning the exact data that has been shared, Airbnb having only revealed that ' $[\mathrm{w}] \mathrm{e}$ want to be good partners to policy makers in Milan and support them with meaningful data on our community and the benefit it brings'. ${ }^{121}$ The home-sharing intermediary appears generally open to - at least in a limited manner - share data with public authorities. It received 188 requests for data access from governments in the first six months of 2016 and provided data in response to 82 of those requests. ${ }^{122}$ In other cities such as New Orleans, the platform moreover shared data pertaining to hosts' names and addresses. ${ }^{123}$ Data sharing is at present self-regulated by the platform. Its 'Community Compact' announces openness to data sharing, stating that it will 'provide cities with the information they need to make informed decisions about home sharing policies'. ${ }^{124}$ The information that is revealed is however relatively generic, including 'Home Sharing Activity Reports' in cities with a significant presence that outline: the total annual economic activity generated by the Airbnb

\footnotetext{
118 Frank Pascquale (n 18).

${ }^{119}$ EP Report of 31 May 2017 on online platforms and the digital single market.

120 https://www.airbnbcitizen.com/moving-forwards-in-milan/.

121 Ibid.

122 https://techcrunch.com/2016/09/02/airbnb-first-transparency-report/

${ }^{123}$ https://skift.com/2016/12/08/airbnbs-new-policies-for-working-with-cities-continue-to-evolve/. ${ }^{124}$ Ibid.
} 
community; income earned by a 'typical' host; the number of hosts having avoided eviction or foreclosure due to sharing income; the number of days a typical listing is rented on the platform and the average number of days guests stay in cities. ${ }^{125}$

It is true that one of the perceived advantages of co-regulatory standards being left to enforce to platforms is that it dispenses them from a need to hand over large quantities of data to public authorities. Yet it is equally evident that for purposes of auditing and review public authorities must be in a position to evaluate whether platforms conform to the determined standards and they cannot do so without access to the data. A number of solutions can be envisaged in this context. The most radical option would be to allow unrestrained access to data to public authorities that however raises a number of concerns for platforms and personal data protection, especially as sophisticated methods of reverseengineering make a total anonymization of data less likely. Softer solutions can however also be envisaged, such as the replacement of large-scale data audits with application programming interfaces (APIs) tailored to government auditing purposes $^{126}$ and we can also think of data-sampling as another solution in this context. While questions of data-sharing will probably have to be determined on a case-by-case basis we now turn to an element that should be present in all contexts of co-regulation, namely an ample involvement of variegated stakeholders.

\section{Towards a Model of Polycentric Co-Regulation}

The early days of the platform economy are marked by the regulatory involvement of nongovernmental norm-generating actors through industry self-regulation. Together with the centrality of subnational authorities, we move away from homogenous top-down model towards a decentralised, reflexive, collaborative and cooperative framework that is process orientated and shaped by standards. This framework is in its essence polycentric as it is characterized by the cooperation of the State, civil society and the market. As life moves from 'walls' to 'webs', law follows. ${ }^{127}$

Polycentricity is inherent to new governance models as unlike traditional conceptions of law that rely on a unitary source of authority 'new governance is predicated upon a dispersal and fragmentation of authority, and rests upon fluid systems of power sharing.'.128 If we adhere to a strict co-regulation approach, only industry and the EU would cooperate to regulate platforms. The argument advanced in this section is that a polycentric regulatory network, encompassing

\footnotetext{
125 Ibid.

126 Arun Sundararajan, The Collaborative Economy: Socioeconomic, Regulatory and Policy Issues, Report carried out for the European Parliament's IMCO Committee (2017) 24, http://www.europarl.europa.eu/RegData/etudes/IDAN/2017/595360/IPOL IDA(2017)595360 EN.p df.

${ }^{127}$ This metaphor originates in Thomas Friedman, The Lexus and the Olive Tree: Understanding Globalization 39-58 (Farrar, Straus and Giroux 1999).

128 Joanne Scott and David Trubek (n 31) 8.
} 
additional stakeholders, would be preferable for it is likely to generate better results and echoes the nature of the platform economy itself.

Co-regulation generates pluralism as binding rules emerge from the interaction of multiple actors outside the hierarchical State structure. ${ }^{129}$ A regulatory mesh has emerged where 'self-regulation and state regulation intertwine and reciprocally complement each other' so that they are 'interdependent in the creation, adoption, application, implementation and enforcement of regulation'. 130 As currently envisaged, co-regulation of the platform economy would lead to a situation where the EU defines legislative standards that are subsequently implemented by platforms. This would be characterised by a number of features, including (i) participation and power sharing as power is not monopolized at supranational level but shared by those participating in the exercise; (ii) multi-level integration as innovative regulatory solutions have been adopted by subnational actors across the Union that now serve as blueprints for regulation elsewhere; (iii) diversity and decentralization given that the impossibility of uniform regulation is acknowledged; (iv) deliberation among multiple stakeholders takes place as the EU doesn't regulate in isolation. The resulting rules would moreover be characterised by (v) flexibility and revisability as they are constantly evaluated and can be swiftly adapted; and (vi) experimentation and knowledge creation as the various concrete applications of the general standards will reveal manifold indicators as to the suitability of a given standard. ${ }^{131}$ It can be readily seen that these features of coregulatory approaches would be further developed if a wider variety of actors were involved.

Polycentric co-regulation would indeed present a number of benefits. It has long been known that polycentric decision-making allows for the concentration of knowledge, which is naturally dispersed across society. ${ }^{132}$ This would remedy the currently prevailing information asymmetries and allow to make regulation fit for purpose. Polycentric co-regulation would be furthermore in line with the 2015 Better Regulation Agenda that promotes evidence-based regulation, including broader consultations and civic engagement. ${ }^{133}$ While polycentricity brings more actors to the table and accordingly generates complexity, the various players have incentives to work together efficiently, solve conflicts and create certainty and stability, objectives that serve as a common denominator. More generally,

\footnotetext{
129 Poul Kjaer, 'The Metamorphosis of the Functional Synthesis: A Continental European Perspective on Governance, Law, and the Political in the Transnational Space' (2010) Wisconsin Law Review 489, 489 ('States remain a central form of ordering but only one among several').

130 Jeanne Bonicci, Self-Regulation in Cyberspace (TMC Asser Press 2008) 199-200.

131 These characteristics have been identified fifteen years ago by Scott and Trubek with respect to new governance. Joanne Scott and David Trubek (n 31) 4-6.

132 Cass Sunstein, Infotopia: How Many Minds Produce Knowledge (Oxford University Press 2006); Henrik Serup Christensen et al, 'Does Crowdsourcing Legislation Increase Political Legitimacy? The Case of Avoin Ministeriö in Finland' (2015) 7 Policy and Internet 25.

133 Communication from the Commission to the European Parliament, the Council, the European Economic and Social Committee and the Committee of the Regions, 'Better Regulation for Better Results - An EU Agenda', COM(2015) 215.
} 
polycentric co-regulation operates in the context of 'decentring regulation' qualified by Black as 'the observation that governments do not, and the proposition that they should not, have a monopoly on regulation'134 as regulation occurs 'within and between other social actors'. ${ }^{135}$ Said approach would in addition be a natural continuance of the current situation, as regulatory conversations on the platform economy are already polycentric in that they are transnational and multi-sectoral. ${ }^{136}$ They also involve a multitude of levels of public authority, most notably local governments, whose regulatory pioneering has provided valuable learning experiences for other regulators. In formulating its recommendations on the collaborative economy in 2016 the Commission as a matter of fact drew inspiration from urban policies across the EU. ${ }^{137}$

Polycentricity can be stimulated by the same technological shift that underlies platforms' emergence. Indeed, the reliance on new digital avenues for participation and deliberation could increase networked policy-making and widen alternative spaces and forms of policy dialogues. This would fit naturally with existing initiatives such as 'Lighten the Load', an online feedback form that allows citizen to express views on EU regulation at any time and on any topic. ${ }^{138}$ Specifically with regards to platforms, the Commission operated an online public consultation between September 2015 and January 2016.139 Open to anyone, it enabled interested parties to communicate perspectives on platforms to the Commission. ${ }^{140}$ Over time such consultations could gain more traction, attract higher numbers of participants and be modified to allow broader scope for individual comment outside pre-determined questions, which was not the case on this occasion. ${ }^{141}$ Out of concerns of space we cannot further elaborate on this initiative but it should be stressed that such openness permits an entire range of industry associations, academic centers, think thanks, companies and platforms to share their views. ${ }^{142}$

\footnotetext{
${ }^{134}$ Julia Black, 'Decentring Regulation: Understanding the Role of Regulation and Self-Regulation in a "Post-Regulatory" World' (n 28) 103.

135 Ibid.

136 On regulatory conversations, see further Julia Black, 'Regulatory Conversations' (2002) 29 Journal of Law and Society 163, 163.

${ }^{137}$ European Commission, 'A European Agenda for Collaborative Economy' (2016),

http://ec.europa.eu/growth/single-market/strategy/collaborative-economy/index_en.htm.

138 https://ec.europa.eu/info/law/better-regulation/lighten-load/suggestions/add. For a critical assessment, see Francesco Sarpi, 'Better for whom?' (2015) 3 European Journal of Risk Regulation 372, 374.

${ }^{139}$ https://ec.europa.eu/digital-single-market/en/news/public-consultation-regulatory-environmentplatforms-online-intermediaries-data-and-cloud.

140 Out of those that participated, only a third however chose to react to questions with a regulatory dimension. European Commission, 'Full Report on the Result of the Public Consultation on the Regulatory Environment for Platforms, Online Intermediaries and The Collaborative Economy', https://ec.europa.eu/digital-singlemarket/en/news/first-brief-results-public-consultation-regulatoryenvironment-platforms-online-intermediaries.

141 https://ec.europa.eu/digital-single-market/en/news/results-public-consultation-regulatoryenvironment-platforms-online-intermediaries-data-and. 142 Ibid.
} 
Platforms themselves have long learned to rely on technology's civic potential. ${ }^{143}$ The probably most prolific example is Uber's introduction of a 'de Blasio' feature on its app for NYC users, indicating how much slower a ride were if the mayor's planned policy was implemented, followed by a link to a petition to oppose it. ${ }^{144}$ The EU should follow suit. It is certainly true that online participation is not free from problems as it creates a cacophony of voices and raises difficult questions of legitimacy, self-selection, undue influence and bias. Yet, evidence mounts that digital tools are having an overall positive impact on civic engagement. ${ }^{145}$ Online consultation enables speedy and broad consultation and crowdsourcing in addition to e-petitions, which are considered to improve dialogue between civil society and lawmakers.146 More widely, technological innovation is impacting on democratic processes through online discussion forums, online petition sites that are now also hosted by Parliaments across the EU, and social media. ${ }^{147}$ Such processes should be increasingly used by the EU, also in respect of the European Citizens' Initiative, and are particularly suited for deliberation on digital transformation, including the platform economy.

This section has made the point for a polycentric approach to co-regulation. In the subsequent section we will see that a widening of the network of contributing agents could bear the potential to lend increased legitimacy to the adopted solutions.

\section{Co-Regulation, Democracy and Legitimacy}

In addition to bearing the promise of better regulatory outcomes polycentric coregulation could also address on-going concerns regarding the legitimacy and democratic quality of supranational law making. If co-regulatory processes are not the exclusive domain of the State or the supranational entity it has conferred competence on, we must wonder how far it can correspond to our ideals of democracy and legitimacy. In circumstances of polycentric co-regulation, the

\footnotetext{
143 Uber has for instance relied on online petitions to pressure law-makers into legalizing the service in their jurisdiction. See 'Florida Needs Uber' https://action.uber.org/florida/, and 'Uber Moves Hawaii' https://action.uber.org/hawaii/.

144 https://techcrunch.com/2015/07/16/uber-launches-de-blasios-uber-feature-in-nyc-with-25-minutewait-times/.

145 Shelley Boulianne, 'Does Internet Use Affect Engagement? A Meta-Analysis of Research' (2009) 26(2) Political Communication 193, 205; Kevin Desouza and Aksay Bhagwatwar, 'Technology-enabled Participatory Platforms for Civic Engagement: The Case of U.S. Cities' (2014) 21(4) Journal of Urban Technology 25.

146 Brian Loader and Dan Mercea, Social Media and Democracy: Innovations in Participatory Politics (Routledge 2012).

147 Beth Simone Noveck, Wiki Government: How Technology Can Make Government Better, Democracy Stronger and Citizens More Powerful (Brookings Institutions 2010); Camilo Cristancho and Jose M. Sabucedo, 'Mobilization through online social networks: the political protest of the indignados in Spain' (2014) 17(6) Information, Communication \& Society 750; Caroline Lee, Do-It-Yourself Democracy: The Rise of Public Engagement (Oxford University Press, 2015).
} 
Union's role shifts to standard setting, coordination, control and facilitation. While it passes initial framework legislation private actors are largely in charge of its implementation as the EU turns into an evaluator and a forum of debate and information that promotes best practices.

Yet, assuming that the procedure behind EU secondary legislation constitutes the apex of democracy and legitimacy would ignore reality. The EU has long been plagued by accusations of democratic deficit and lack of legitimacy. ${ }^{148}$ Even if we abstract from this meta-diagnosis and look at the concrete instance of regulating platforms two realistic options emerge. First, the passing of top-down legislation influenced by industry preferences, that are however voiced through lobbying behind closed doors, or, alternatively, a co-regulatory process where such involvement is made explicit and transparent. Indeed, the claim advanced in this closing section is that alternative methods of governance can be seen as not necessarily undermining but rather the stimulating democratic deliberation in the EU.149

Modes of governance reflect a concern on behalf of the EU to secure higher legitimacy for its policymaking. ${ }^{150}$ Scott and Trubek observed that their emergence 'may be explained in part by the contested legitimacy' of the supranational legislative process'.151 In contrast to self-regulation, co-regulation offers opportunities to bridge such concerns through the very technological shift that underlies platforms. In a co-regulatory platform-regulation process, the number of actors intervening can be radically expanded as technology itself can facilitate stakeholder involvement in ad hoc consultations but also in giving new lifeblood to existing mechanisms, such as the European Citizens' Initiative. ${ }^{152}$ We however agree with Verbruggen that 'if co-regulation is to strengthen the legitimacy of EU governance, the EU should set out in greater detail and in a consistent fashion what it aspires to do with co-regulation, under what conditions co-regulation may be applied and what effects co-regulation may generate'.153

The emergence of a participatory and collaborative governance model in which public authorities, industry representatives, society and other stakeholders co-regulate feeds into traditional regulatory bodies' legitimacy crisis triggered by the emergence of the Internet, echoed by the until the early 2000 s dominant

\footnotetext{
148 Andreas Follesdal and Simon Hix, "Why is there a Democratic Deficit in the EU: A Reply to Moravcsik' (2006) 44 Journal of Common Market Studies 533.

149 See further William Simon and Charles Sabel, 'Epilogue: Accountability without Sovereignty' in Gráinne de Búrca and Joanne Scott, Law and New Governance in the EU and the US (Hart Publishing 2006).

150 Dagmar Schiek, 'Private Rule-Making and European Governance - Issues of Legitimacy' (2007) 32 European Law Review 449.

151 Scott and Trubek, 17.

152 Article 11(4) TEU.

153 Paul Verbruggen, 'Does Co-Regulation Strenghten EU Legitimacy?' (2009) 15 European Law Journal $425,426$.
} 
perception that the Internet knows no borders and escapes territorial regulation. ${ }^{154}$ In the future we are likely to be faced with the question of the democratic legitimacy of the crowd as technological developments enable novel forms of participation and deliberation. This leads us to observe that as digital technologies transcend geographic boundaries and yield localized results, they also present the opportunity to develop a networked public sphere that can transform policymaking processes for the better. Multi-stakeholder bodies that include governments at various scales, industry, consumers and providers but also social scientists and other stakeholders provide room for deliberation whereas platform self-regulation and regulation by code do not. ${ }^{155}$ As such we might argue that coregulation can be more consistent with democratic, participatory, and representative ideals, especially where it operates as a polycentric process involving prosumers and other stakeholders. A process fashioned in this manner recognizes pluralism and allows for decentralization in addition to facilitating experimentation. We should not least stress the transparency gains that can be achieved through such an approach where firms influence the regulatory scheme in an open polycentric process rather than through lobbying. No doubt, the above is the view of an optimist. Yet, in light of the arguments against self-regulation and top-down regulation advanced above they are worth experimenting with.

\section{CONCLUSION}

This essay has examined various regulatory design options for the platform economy, bearing in mind platforms' internal operation as well as external consequences. Throughout history disruptive technologies have transformed industries, markets and legal systems. From this perspective, the emergence of digital data-driven platforms is not unique. What makes it particularly challenging from a regulatory perspective, however, is the pace with which it progresses, which distinguishes digital transformation from earlier industrial revolutions. This challenges not least regulators that need to define the form and substance of platform regulation. Focusing largely on the first aspect, we have concluded that co-regulation must be favoured to top-down or self-regulation, at least in these early days of the platform economy.

Co-regulatory solutions bear the potential to marry the benefits of both regulatory paradigms in harnessing the effectiveness of platform's involvement in the regulatory process with public oversight. In this process, which relies on cooperation and dialogue, platforms and public authorities are collaborators rather

154 This is best illustrated by John Perry Barlow, A Declaration of Independence of Cyberspace (1996), https://www.eff.org/cyberspace-independence ('[y]ou have no moral right to rule us nor do you possess any methods of enforcement we have true reason to fear').

155 For a discussion, see Lawrence Lessig, Code: Version 2.0 (Basic Books 2006) 6-7. 
than adversaries. Such a process can allow for more informed decision-making, easier enforcement, and continuous review and assessment. The experimental nature of this process allows for mutual learning and the identification of best practices as well as for a dynamic adaptation of the relevant rules over time.

It has moreover been argued that technological innovations underlying the platform economy should be mobilized to capture the polycentric nature of coregulation and involve a greater number of stakeholders. Co-regulation in itself bears the promise of polycentric governance capable of bringing multiple actors to the table, and, ultimately, addressing some of the legitimacy concerns plaguing supranational regulation. In using platforms as modes of deliberation and participation, the European Commission could ensure that the regulatory outcome is one that strikes an appropriate balance between the multiple interests involved in helping the digital economy thrive in generates certainty and trust while also protecting stakeholders. 